УДК 004:327.5

\title{
О РОЛИ ИНФОРМАЦИИ В МИРОТВОРЧЕСКОЙ ДЕЯТЕЛЬНОСТИ СОВЕТА БЕЗОПАСНОСТИ ООН
}

\section{Балашова Мария Александровна} к.э.Н., доцент

Попова Юлия Сергеевна Попова Анна Александровна Балашова Анастасия Михайловна ФГБОУ ВО «Байкальский государственный университет»

Аннотация: Ведущей тенденцией развития современной мировой экономики и, соответственно, всех ее субъектов, является глобализация 4.0. Лежащие в ее основе информационные технологии, актуализируют на повестке дня, в числе прочих, вопросы об эффективности созданных, в большинстве своем, в XX в. международных организаций. В статье анализируется работа одного из главных органов ведущей в мире комплексной международной межправительственной организации Организации Объединенных Наций - Совета Безопасности по одному из ключевых направлений его деятельности - миротворчеству. Делается вывод о том, что эффективность рассматриваемой структуры и, соответственно, ее деятельности, не должна в XXI в. подвергаться сомнению. Предлагается нивелировать угрозы, которые несет в себе глобализация 4.0., сделав ставку на максимизацию полезностей, приносимых информационными технологиями.

Ключевые слова: Информатизация, информация, глобализация 4.0., международные организации, Совет безопасности $\mathrm{OOH}$, миротворческая деятельность.

\section{ON THE ROLE OF INFORMATION IN PEACEKEEPING UNITED NATIONS SECURITY COUNCIL}

\section{Balashova Mariia Aleksandrovna Popova Yulia Sergeevna Popova Anna Aleksadrovna Balashova Anastasiia Mikhailovna}

\footnotetext{
Abstract: The leading trend in the development of the modern world economy and, accordingly, all its subjects, is globalization 4.0. The underlying information 
technologies, among others, actualize the issues of the effectiveness of international organizations created, for the most part, in the twentieth century. The article analyzes the work of one of the main organs of the world's leading complex international intergovernmental organization - the United Nations - the Security Council in one of its key areas of activity - peacekeeping. It is concluded that the effectiveness of the structure under consideration and, accordingly, its activities should not be questioned in the XXI century. It is proposed to neutralize the threats posed by globalization 4.0., placing a bet on maximizing the benefits brought by information technologies.

Keywords: Informatization, information, globalization 4.0., international organizations, UN Security Council, peacekeeping

Как известно, к ключевым особенностям развития современной мировой экономики принято относить такие тенденции как: интернационализацию производства и капитала, транснационализацию, либерализацию, интеграцию, регионализацию, неравномерность экономического развития, расширение масштабов глобальных проблем, постиндустриализацию и информатизацию. Последние, по мнению специалистов, коренным образом меняют содержание всей системы международных экономических отношений и, соответственно, приводят к необходимости конструктивных изменений в подходах к построению и реализации как внутри [1 С. 58], так и внешнеэкономической политики стран [2 С. 263].

Набирающая обороты глобализация 4.0 актуализирует вопросы разработки новых механизмов организации сотрудничества стран и их субъектов, в первую очередь, на макроуровне экономического анализа. Считается, что действующие в настоящее время правила, процедуры, установленные в большинстве своем в XX в., не дают больше возможности находить оптимальные решения. Проникающие во все сферы человеческой деятельности информационные технологии, несут в себе не только очевидные преимущества, но и формируют новые угрозы. Устоявшаяся за последние десятилетия структура национальных и наднациональных организаций, способы их функционирования оказываются в огромном количестве случаев не способными их полностью нивелировать.

Помимо таких «нюансов» как повышение уровня информатизации национальных экономик, специалисты говорят о том, что в мире не осталось фактически ни одной международной организации, которая бы эффективно выполняла свои функции в условиях информационного этапа развития 
мировой экономики [3]. Актуальным на повестке дня является вопрос о том, стоит ли их сохранять, реформировать или необходимо создать новый фундамент выстраивания международных экономических отношений [4]. Сомнению подвергается даже эффективность такой крупнейшей в мире комплексной международной межправительственной организации (ММПО) как система организаций объединенных наций $(\mathrm{OOH})$.

В своем исследовании мы не ставили цели найти ответ на вопрос о будущем всех ММПО в условиях глобализации 4.0. Мы попытались проанализировать работу только одного главного органа $\mathrm{OOH}$, единственного в мире, чьи решения являются обязательными для реализации - Совета безопасности (СБ) и только по одному, на наш взгляд, ключевому направлению, ради регулирования которого и начиналась вся история массового создания международных организаций еще в 1919 г. - предотвращение конфликтов в мире, что сегодня по праву считают «жемчужиной в короне ООН». Данный выбор представляется вполне обоснованным, поскольку, если окажется, что если СБ не стоит больше трактовать в качестве эффективной легитимной структуры, то вполне закономерным может быть вывод о том, что будущее большинства ММПО, принимающих решения исключительно рекомендательного характера, действительно неопределенно.

Ключевым в нашем исследовании стал вопрос о том, реально ли наступил тот момент, когда информация, которую специалисты так «возвеличили», придав ей смысл пятого фактора производства, основы ключевых капиталов стран XXI в. (человеческого, информационного, интеллектуального (ЧК, ИнфК, ИнтК)) в случаях существования проблем:

- технического плана - слабого внедрения информационного ресурса в цепочки жизненных циклов производимых товаров или оказываемых услуг;

- содержательного характера - отсутствия защитных механизмов от негативных воздействий со стороны внешних ЧК, ИнфК и ИнтК, способна привести к ситуации невыполнения СБ возложенной на него в числе прочих, функции миротворчества.

В настоящее время, несмотря на процессы постоянного углубления политического диалога между странами, ведущие из них - страны основательницы Ядерного клуба, понимая опасность сохранения военной агрессии и необходимость обеспечения национальной безопасности, не только продолжают сохранять свой военный потенциал, но и проводят соответствующую активную экспортную политику (табл. 1). 
Говорящим в данной ситуации также является и факт того, что количество «горячих точек» на планете, к сожалению, не имеет тенденции к явному снижению [5, 6]. Так, в 2014 г. в мире было зарегистрировано 64 миротворческие операции, в 2015 г. - 63, 2016 г. - 62, 2017 г. - 63, 2018 г. [7 С. 110 - 111]. Только на конец 2020 г. в 31 стране мира шли войны и столкновения. Они постоянно вспыхивают на территории, в основном, развивающихся стран мира и представляют собой в своей львиной доле сепаратистские движения.

Безусловно, основная роль в их урегулировании лежит на плечах официального руководства страны/стран участниц. Однако, зачастую на практике возникают такие ситуации, когда соответствующие субъекты оказываются бессильными, и тогда международное сообщество (в лице СБ) подключается к их разрешению.

Таблица 1

Сравнение ряда показателей, характеризующих состояние военной сферы стран с правом ВЕТО

\begin{tabular}{|c|c|c|c|c|c|}
\hline Год & Китай & США & Великобритания & Франция & Россия \\
\hline \multicolumn{7}{|c|}{ Военный импорт (значение индикатора тренда SIPRT) } \\
\hline 2007 & 1677000000 & 820000000 & 776000000 & 74000000 & 100000000 \\
\hline 2017 & 1117000000 & 547000000 & 899000000 & 65000000 & 34000000 \\
\hline \multicolumn{7}{|c|}{ Объем военного экспорта (значение индикатора тренда SIPRT) } \\
\hline 2007 & 510000000 & 7866000000 & 974000000 & 2410000000 & 5528000000 \\
\hline 2017 & 1131000000 & 12394000000 & 1214000000 & 2162000000 & 6148000000 \\
\hline \multicolumn{7}{|c|}{ Обьем военных расходов (\% от расходов центрального правительства) } \\
\hline 2007 & 11,62 & 18,44 & 5,81 & 5,11 & 14,55 \\
\hline 2016 & 11,78 & 14,17 & 4,87 & 4,82 & 17,48 \\
\hline \multicolumn{7}{|c|}{ Расходы на оборону (\% от ВВП) } \\
\hline 2007 & 1,91 & 3,84 & 2,14 & 2,28 & 3,34 \\
\hline 2017 & 1,86 & 3,14 & 1,80 & 2,24 & 4,20 \\
\hline \multicolumn{7}{|c|}{ Число военнослужащих (\% т общей численности рабочей силы) } \\
\hline 2007 & 0,37 & 1,00 & 0,51 & 1,20 & 1,93 \\
\hline 2016 & 0,34 & 0,82 & 0,44 & 1,00 & 1,90 \\
\hline
\end{tabular}

Примечание: составлено авторами на основе обобщения источников [Официальный сайт Statista.com [Электронный ресурс]. Режим доступа: https://de.statista.com/statistik/ (дата обращения 19.03.2021)], Официальный сайт Trendeconomy.ru [Электронный pecypc]. Режим доступа: https://trendeconomy.ru/data/ (дата обращения 19.03.2021)]

На первом этапе СБ настоятельно советует прекратить конфликт мирным способом. В случае его перехода в вооруженную стадию (либо ее не 
прекращения), СБ призван учреждать соответствующие операции по поддержанию мира, определять рамки их полномочий и мандат, руководствуясь Уставом ООН, а также Резолюциями 60/180, 1325, 1612 (2005), 1645(2005), 2467 (2019), 2538 и др. Большинство из таких операций предполагает участие военнослужащих, которые следят за соблюдением режима прекращения огня, создают буферную зону, тем самым обеспечивая безопасную обстановку для проведения переговоров.

Практика свидетельствует о том, что огромную роль, как в разжигании соответствующих конфликтов, так и в процессах их осуществления действительно играет информационный фактор [8 С. 393]. Ни для кого не является секретом, что, в настоящее время, используя мировые и национальные средства массовой информации (СМИ), по всему миру осуществляются призывы к сепаратистским движениям от третьих стран и отдельных движений, что должно трактоваться как прямое посягательство на суверенитет атакуемых государств, решительно осуждаться и приравниваться к вмешательствам во внутренние дела суверенных государств, нарушающим принцип неприкосновенности территориальной целостности, закрепленный в Уставе ООН. Мы решительно осуждаем любые вмешательства в дела любого суверенного государства и считаем недопустимым распространение ложных информационных вбросов, дискредитирующих легитимно избранное правительство суверенных государств.

Учитывая явное негативное воздействие информационных атак на миротворческую деятельность СБ ООН и осуществляя попытку поиска путей повышения эффективности работы соответствующей структуры, полагаем важным рассмотреть ее руководству следующие инициативы, направленные на нивелирование стоящих перед ней угроз.

Во-первых, фактом является ставка на принцип реализации нисходящего подхода к разрешению конфликтов, в рамках которого СБ ООН и его миротворческий контингент стремятся к выполнению роли посредника исключительно между лидерами враждующих сторон. По нашему мнению, данный подход не отвечает реалиям сегодняшнего дня. Мы полагаем, что для успешной реализации поставленных целей по обеспечению мира, целесообразно дополнить действующий нисходящий подход восходящим. На примере Сирии, Афганистана и Южного Судана мировое сообщество в полной мере убедилось, что мирные соглашения не приводят к миру на местах, поэтому, считаем вполне обоснованным, заявлять о необходимости 
разработок стратегий миротворческих операций, в основе которых будет лежать мнение местных жителей и лидеров местного уровня. Однако при этом стоит абсолютно четко понимать, что право на самоопределение не должно легитимизировать право на сецессию, тем более, что она может еще более обострить этнические проблемы [9].

Данный шаг, на наш взгляд, является принципиально важным. Вопервых, он позволит снизить воздействие внешних информационных атак на принимаемые решения, а, во-вторых, станет источником достоверной внутренней информации, столь необходимой в соответствующей ситуации.

В современном мире многонациональных государств, оказывается невозможным найти единственное правильное решение, выслушав исключительно позицию их официального руководства. Властям не всегда удается равнозначно реализовать на практике принцип сохранения территориального единства государства и одновременно принцип признания народов и национальностей равноправными. Очевидно, что в случае необходимости выбора принцип территориальной целостности берет верх над принципом национального самоопределения, под которым руководство зачастую понимает самоопределение всей нации единого государства.

Во-вторых, считаем необходимым закрепить право обсуждения соответствующих вопросов, организацию и проведение переговоров всех сторон конфликтов исключительно за официальным структурами и только в формате оффлайн. Мы согласны с тем, что прерогативой именно мирового сообщества должна стать помощь в организации и проведении безопасных переговоров для всех сторон потенциального спора, как территориального, так и касающегося вопросов самоопределения, что именно переговоры, а не вмешательство являются цивилизованным способом решения проблем в современном мире. Однако, соответствующие переговоры не должны вестись в виртуальном пространстве. Следует блокировать любой, разжигающий агрессию контент, который появляется на просторах Интернет-пространства, тем более до момента принятия соответствующих официальных решений.

Считаем допустимым разморозить деятельность Совета по опеке и вменить в его функции:

- разработку единых условий, обосновывающих вмешательство мирового сообщества в разрешение разногласий, как территориального характера, так и касающихся вопросов самоопределения народов (в 
соответствии с Уставом ООН, государства не должны вмешиваться в дела, входящие во внутреннюю компетенцию любого другого государства);

- разработку унифицированного механизма, разрешения разногласий, как территориального характера, так и касающихся вопросов самоопределения народов;

- постоянный мониторинг ситуации;

- организацию и проведение соответствующих переговоров, как стадию, предшествующую заседаниям СБ ООН, на которых на повестке дня появляются вопросы уже о введении миротворческих сил. Считаем, что во избежание кровопролитий и нарушения мира определяющим должен стать принцип превентивности.

Ставка не на СБ, а на Совет по опеке делается нами исходя из того факта, что формат соответствующих переговоров в рамках первой структуры, особенно в последние годы не всегда дает возможность нивелировать поляризацию региональных интересов стран с правом Вето в регионах конфликтов [10 С. 19].

В-третьих, учитывая очевидный дисбаланс в страновой структуре миротворческих сил $\mathrm{OOH}$, имеющий своим следствием самоличное наделение странами, обладающими ее самым большим контингентом, самих себя исключительными правами на территории «горячих точек», считаем важным способствовать расширению присутствия в ее составе представителей развитых государств мира. В настоящий момент специалисты трактуют их участие в миротворческих миссиях как чисто символическое. Фактически их основная роль сводится в настоящее время к процессу разработки мандатов. Данный шаг должен способствовать снижению количества противоправных действий со стороны миротворцев в точках конфликтов и естественным образом повышать эффективность самой структуры СБ. В настоящее же время на страницах онлайн изданий выкладываются огромные блоки информации о поведении представителей «Голубых касок» на территории иностранных государств, дискредитирующих соответствующую структуру в целом.

В частности, в настоящее время численность всего военного персонала $\mathrm{OOH}$ достигает порядка 90000 военнослужащих, представленных национальными армиями со всего мира (табл. 2). 
Таблица 2

Взносы стран с разбивкой по миссиям и типам персонала, чел.

(на 31 января 2021 г.)

\begin{tabular}{|c|c|c|c|c|c|c|c|c|c|}
\hline Китай & США & $\begin{array}{c}\text { Фран- } \\
\text { ция }\end{array}$ & $\begin{array}{c}\text { Великобри- } \\
\text { тания }\end{array}$ & Россия & $\begin{array}{c}\text { Бан- } \\
\text { гладеш }\end{array}$ & $\begin{array}{c}\text { Эфио- } \\
\text { пия }\end{array}$ & Индия & $\begin{array}{c}\text { Паки- } \\
\text { стан }\end{array}$ & Руанда \\
\hline \multicolumn{10}{|c|}{ Миссия ООН в Южном Судане UNMISS } \\
\hline 1054 & 8 & - & 5 & 12 & 1573 & 2155 & 2388 & 274 & 3364 \\
\hline \multicolumn{10}{|c|}{ Многопрофильная комплексная миссия ООН по стабилизации в Мали MINUSMA } \\
\hline 422 & 8 & 34 & 256 & - & 1646 & 1 & - & 153 & - \\
\hline \multicolumn{10}{|c|}{ Миссия ООН в Ливане UNIFIL } \\
\hline 419 & - & 473 & - & - & 112 & - & 781 & - & - \\
\hline \multicolumn{10}{|c|}{ Смешанная операция Африканского союза ООН в Дарфуре UNAMID } \\
\hline 318 & - & - & - & - & 167 & 829 & - & 1072 & 1163 \\
\hline \multicolumn{10}{|c|}{ Стабилизационная миссия ОOН в ДРК MONUSCO } \\
\hline 230 & 3 & 6 & 3 & 15 & 1861 & - & 2046 & 1978 & - \\
\hline \multicolumn{10}{|c|}{ Миссия ООН по референдуму в Западной Сахаре MINURSO } \\
\hline 11 & - & 3 & - & 11 & 20 & - & 2 & 13 & - \\
\hline \multicolumn{10}{|c|}{ UNFICYP } \\
\hline 5 & - & - & 253 & 9 & - & - & 1 & 3 & - \\
\hline \multicolumn{10}{|c|}{ Организация по наблюдению за выполнением условий перемирия UNTSO } \\
\hline 4 & 2 & - & - & 4 & - & - & 2 & - & - \\
\hline \multicolumn{10}{|c|}{ Многопрофильная комплексная миссия ООН по стабилизации в ЦАР MINUSCA } \\
\hline- & 8 & 15 & - & 10 & 1313 & - & - & 1252 & 1826 \\
\hline \multicolumn{10}{|c|}{ Итого } \\
\hline 2463 & 29 & 531 & 517 & 61 & 6693 & 6291 & 5419 & 4746 & 6364 \\
\hline
\end{tabular}

Примечание: составлено авторами на основе обобщения источников [Официальный сайт "Операции ООН по поддержанию мира". [Электронный ресурс]. - Режим доступа: https://peacekeeping.un.org/ru/military (дата обращения: 27.03.2021)]

Самый многочисленный контингент в нем имеют не страны-постоянные члены $\mathrm{OOH}$, а развивающиеся государства, такие как Бангладеш, Руанда, Эфиопия, Индия и др. [11].

Среди стран-основательниц Ядерного клуба, самый большой контингент миротворцев в $\mathrm{OOH}$ имеют китайские миротворческие подразделения. Они разбиты на 28 самостоятельных единиц в 10-ти категориях: пехота, инженеры, транспортники, медперсонал, силы быстрого реагирования, отряды охраны, вертолётные группы, транспортная авиация, беспилотные части и надводный флот. Соответствующие структуры настроены на дальнейшее углубление сотрудничества с ООН в сфере миротворчества. Более того, китайская сторона 
готова наращивать своё участие в конкретных миссиях, выполняя тем самым, свои обязанности как крупная держава.

В-четвертых, основываясь на фактах уже реализованных на практике миротворческих операций, считаем обоснованным внесение корректировок в действующие программы обучения и подготовки миротворческих сил ООН. Речь идет о необходимости формирования в среде миротворческого контингента знаний об истории каждого конфликта, культуре, традициях, языке принимающей страны, в которой им предстоит работать, для оказания действительной поддержки местному населению в построении мира. Другими словами, используя терминологию информационного общества, речь идет о необходимости совершенствования, а в ряде случаев - еще только формирования таких принятых в гражданском обществе категорий как ЧК, ИнфК и ИнтК миротворческого контингента.

Полагаем, что реализация на практике предлагаемых решений может способствовать снятию с повестки дня вопросов об эффективности СБ ООН в целом и его миротворческой деятельности, в частности. Данная структура должна продолжать свою работу, но с учетом новых реалий. Необходимо нивелировать угрозы, которые несет в себе глобализация 4.0., сделав ставку на максимизацию полезностей, приносимых информационными технологиями.

\section{Список литературы}

1. Тагаров Б. Ж. Особенности новых форм реализации человеческого капитала в цифровой экономике / Б. Ж. Тагаров // Историко-экономические исследования. - 2020. - Т. 21, № 1. - С. 56-79.

2. Макарова Г. Н. Трансформация критериев эффективности экономической деятельности стран в условиях современной модели глобализации / Г. Н. Макарова, В. А. Рудяков // Историко-экономические исследования. - 2019. - Т. 20, № 2. - С. 261-293.

3. Постел-Винай $\quad$ К. (2020) Глобализация 4.0 и новые модели международного сотрудничества // Вестник международных организаций. - Т. 15. —№ 2. C. 82-92 (на русском и английском языках). DOI: 10.17323/19967845-2020-02-04

4. Шваб К. Глобализация 4.0. Новая архитектура для четвертой промышленной революции [Электронный ресурс]. Режим доступа: https://www.foreignaffairs.com/articles/world/2019-01-16/globalization-40 (дата обращения: 16.03.2021) 
5. Холодковский К. Г. Особенности сепаратизма в Западной Европе XXI века / К. Г. Холодковский // Южно-российский журнал социальных наук. 2018. - T. 19. - № 2. С. 27-37.

6. Будущее миротворческих операций Организации Объединенных Наций: выполнение рекомендаций Независимой группы высокого уровня по миротворческим операциям. Доклад Генерального секретаря о рекомендациях (2015). OOH, A/70/357-S/2015/682. [Электронный ресурс]. Режим доступа: Режим доступа https://undocs.org/ru/S/2015/682 (дата обращения 22.03.2021)

7. Худайкулова А. В. Миротворчество ООН в XXI веке: основные векторы реформ и практика их имплементации / А. В. Худайкулова // Южнороссийский журнал социальных наук. - 2019. - Т. 20. - № 4. - С. 109-126.

8. Самаруха А. В. Информационно-коммуникационные технологии в аспекте управления социально-экономическим развитием региона на основе финансового и бюджетного проектирования / А. В. Самаруха, Д. И. Сачков // Известия Байкальского государственного университета. - 2016. - Т. 26, № 3. C. 392-399.

9. Горовиц Д. Разрушенные основания права сецессии / Пер. с англ. Р. Э. Бараш // Власть. - 2013. - № 11.

10. Никитин А. И. (2016). Миротворчество ООН: обновление принципов, реформирование практики / А. И. Никитин // Мировая экономика и международные отношения. - 2016. - № 60(3). - С. 16-26.

11. Официальный сайт "Операции ООН по поддержанию мира". [Электронный ресурс]. - Режим доступа: https://peacekeeping.un.org/ru/military (дата обращения: 25.03.2021).

(C) М.А. Балашова, Ю.С. Попова, А.А. Попова, А.М. Балашова, 2021 